\title{
Media Influence in Promotion Mix
}

\author{
Rajan Arapi \\ University "Haxhi Zeka", Peje \\ Email: rajan.arapi@unhz.eu
}

\section{Drita Kruja}

Shkodra University "Luigj Gurakuqi" Email:dkruja@unshk.edu.al

\section{Doi:10.5901/ajis.2015.v4n2s1p176}

\begin{abstract}
This papers aims to analyse what is the influence of media in mix promotion. In today global economy having a clear vision of marketing strategy is fundamental for the companies to succeed and have competitive advantages in the market. The promotion mix of an existing or new product requires a wider treatment of its advertisement in front of the consumers. Not always the concept of a promotional spot or of an interesting and attractive promotional idea is considered a solution to advance the product in promotional aspects. To determine a promotional campaign and a concrete idea of what, how, when and where we want to promote our product is considered to be a precondition to continue with next steps of product promotion or advertisement. After accomplishing the above mentioned preconditions in this case we have design the complete idea to promote the product. The next stage, that is considered not less important, is the communication channels selection that means selection of ways that we desire to communicate with our existing and potential consumers. The next stage of a promoting campaign is testing, measuring the public, viewership and the audience in which is transmitted the promoting message. In this case the rating is an very delicate issue, requires a special treatment because through this element we can measure the public respectively viewership based in households percentage. The effectiveness of a promotion campaign, the evaluation that the companies made during the product promotion or after the promotion campaign, is determinant if the campaign had successful results. The above mentioned issues are some of the elements analyzed in this research. In the end are illustrated by case studies and conclusions.
\end{abstract}

Keywords: Promotion mix, marketing mix, advertising, consumer, media

\section{Introduction}

The promotion mix includes all the marketing system means, whose task is the communication with the potential consumers. (Kotler, 2010) The purposes of using promotion, as an instrument of marketing mix, is numerous and several types. The promotion can influence to the image of the company or to the new products of the company, by informing the consumers with the features of the existing and new products that will be conducted to the market. While for the products in decline phase, the company tries to conserve those products' popularity. This impact in increasing the effectiveness of distribution channel and contributes in sales and purchase contracts to be efficient.

The promotion mix is an elastic element with which the company communicates with the market. The role of the promotion in company's business has a characteristic dynamism. (Veseli, 2010) The promotion encourages and supports the company, but cannot create a sale basis without the support and efficient performance of other activities of marketing mix.

To effectively develop the promotion in the concrete case the production companies in Kosova in many cases collaborate with the marketing agencies and media for massive communication.

\section{Promotional Message}

The propaganda is more than e good understood slogan. Is information that aims to attract the attention of audience - the name and the location of a company, benefits of a new product, important fair in a very special place, etc.

The advertisements can contain words, pictures, different actions, scenes and attractive views, symbols that 
marketers use to influence in consumer's perception. Generally the messages contain different appeals such:

- Rational appeals (focused in dimensions of benefits, product's selection or brands).

- Emotional appeals (seek to create good feels for the products creating emotions to the consumers).

- Humorous appeals ( is intended the sense of humour for the audience), in general can be effective but for a short time

- Moral appeals (try to convince the audience that using or accepting the idea is the real thing), the advertisement that oppose the failure always use the moral appeal. (George Belch, Promotion \& Advertising, 2009)

Usually creating messages and appeals for the promotion is a task of specialized persons within the company or promotion agencies. These people try to demonstrate the product's advantages with the aim to attract and keep the consumer's attention and increase their interest and desire.

However, for many companies and product only the words cannot determine the effectiveness in communication, but is the picture or the impression gained from the promotion. If we analyze some advertisements with pictures a part of these companies use only one picture to transmit their message. However, the need for a name, brand and picture is an effective way to transmit the intended message of these advertisements, for refined simplicity and classic design.

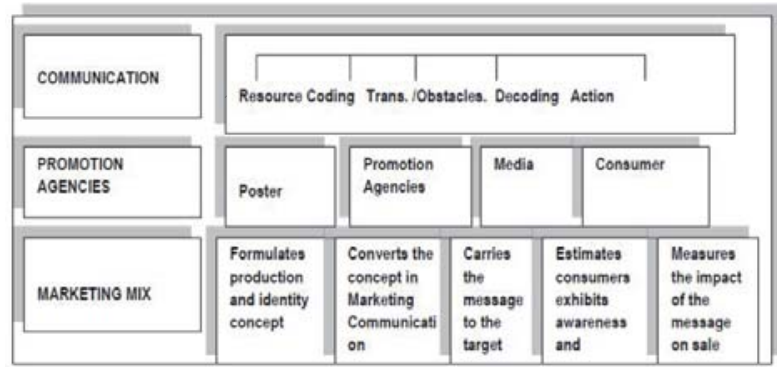

Figure 1. Marketing Mix communication model

Source: Veseli Nexhbi, Promocioni, pg.34, Tetovë

\section{Communication Channels}

The channel is the manner by which the communication travels from the resource or sender to the receiver. In a wider context there exist two types of communication channels: personal and. (Wallack, 2011)

Personal channels of communication are the direct contacts (face to face) for the target individuals or groups. The sellers serve as personal channel when they transmit the message to the potential consumers. The social channels of communications as friends, collaborators, colleagues or family represent also personal channel. Very often they represent recounting (backbiting) that is a powerful resource of the information for the consumer.

Impersonal channels of communication are those channels that transmit messages without personal contact between the seller and receiver. The impersonal channels in general are called massive communications, because the message is send to some individuals in the same time. For example: a television advertisement in main programs can be watched by 1 million persons for one night. The impersonal channels of communication are found in two mayor types: printed and electronic. In the printed media made part newspapers, journals, direct post and billboards, while in electronic media made part the radio and television.

\subsection{The Receiver / Decoding}

As receivers are considered the persons with whom the sender and receiver share the opinions or information. In principal the receivers are consumers in overall market or the public that read or listen or see the message and decode this message. (George Belch, Promotion \& Advertising, 2009)

In order to have an efficient communication, the decoding process of the message to the receiver must matched with sender decode. This means that the receiver understand and explain in a clearly way the message that want to present. A communication is considered efficient when it exists a common language between both parties. 


\subsection{Receiver Analyze and Total Public Definition}

In order to have an efficient communication with the consumers, the marketing agents must understand the public that in general have knowledge or believes to the company's products or services, and how to contact with the public with the aim to influence in its decisions. (Haresh, 2011) The marketing agents must know how will act the market in different resources of communications or different types of messages. Before deciding the variability according to the resource, message and channel, the promotional planers must understand the possible results according to each of these factors. This part is concentrated to the way in which the public is identified and with the process through which will pass when it reacts in the promotion message. The information serves as a base for the evolution of communication invariability.

On the other side actually the marketing communication process starts with the definition of the public to which are directed the efforts of promotion proclamation. The total public can be composed by individuals, specialized markets, market segments or general opinion or massive public. The marketing agents in this case should be approached in different manners, separately to each of groups.

The total market can be composed from individuals with special needs and for whom the message is designed. Very often this means interpersonal communication and very often is achieved by contact sales. .

The second level of collective audience is composed by the groups. The marketing agents very often communicate with a group of people that decide or have influence in purchasing decisions.

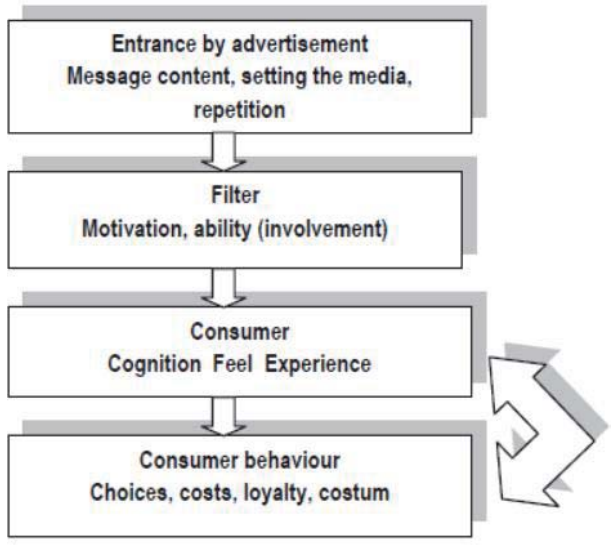

Figure 2. The framework of advertisement studding

Resource: (Lawrence M. Wallack, (2011), Mass Media Campaigns: The Odds against Finding Behavior Change, pg.46)

\subsection{Media Selection}

The marketers try to find the best media in order to achieve the target audience with the advertisement messages. Often they make a mix of media to communicate. To select different media means (newspapers, journals, TV programs, radio, etc.) they make an evaluation of these based to some requirements:

$>$ Television, the reason why the marketers choose this type of media are the advantages that offers the television, where the message is presented through the speech and the picture. Here the product can be presented before the audience in their real form, are tested before the audience and can be showed their useful.

$>$ Radio, often is selected as an alternative choice to present the message and because the radio impacts the target audience. As an advantage of the radio we can mention: the person's voice influence direct to the listeners, the possibility to transmit the message with music, the velocity of transmitting the message, etc. Receiving messages through radio is advantage because the people can listen without interrupting their jobs, while they're driving or eating.

$>$ Direct mail, marketers' aim is to transmit the message to the target market. In nowadays many of consumers receive catalogues, brochures, different calls, etc. This form of promotion contains more information than 
commercial televisions, newspapers and other types of media,, when are clearly explained and described the complex and detailed things.

$>$ Internet actually is qualified, by a big number of organizations and world companies, as a very attractive media to promote. As well this media is used in Kosova for the companies to promote their products and services. The marketers in this case combine the words with the pictures and sometimes also the voice to achieve the local and global target markets. The advantages of using the internet are: the low price, the possibility to receive the message 24hours/day and is seen by a big number of persons in entire world.

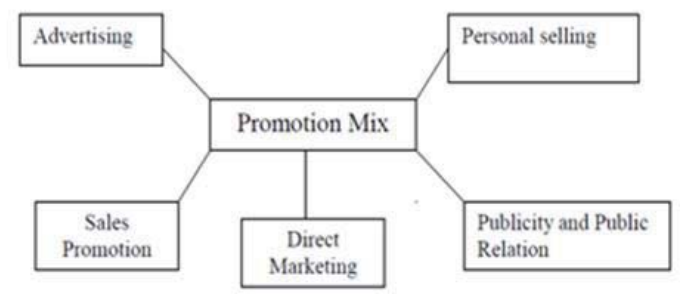

Figure 3. Elements of the Promotion Mix

\subsection{Preliminary Testing of Advertisement}

After the company's purposes and the budget is foreseen, after the creation of the message and media selection the marketers work is testing the advertisement. This includes the responsibility and audience's behaviour toward the advertisement before the campaign. If the audience does not react good the marketer's task is to modify the advertisement, a preliminary test and then to promote it in the media. (Nexhbi Veseli, 2009)

Case study: Bibita Group, is a company which arrange the juice and wet wipes products. This company pays an important attention to media selection and promotion campaigns. Has to be mentioned, that the promotional spots realized by this company, are very attractive, because of the simple fact that contains messages that wake the curiosity of the viewers and potential consumers.

The transmission of the spots in electronic media "Bibita Group" realizes in favourable and the most viewed periods. The marketers take into consideration the TV surveys of statistical dates that possess the media and also the monitoring responsible organizations. Until now the company has been determine in the transmission of its promotions within the recreational programs that except the youth people are watched by familiars and in this case are the potential consumers of Bibita Groups products. The advertisements are transmitted in the morning programs in the Kosova Public Television (RTK), and than before the transmission of the central news edition in RTK and during the telenovela and evening films.

As well as in Radio, usually they select the two station radio that have obedience and reliability in Kosovo, Radio Kosova and Radio Dukagjini, and the time to transmit have been the most listen time, in different programs and advertisement time.

The company, time to time, have promote its products in newspapers, journals, billboards and different sponsoring, especially in case they have new promotional offers, new products, special offers etc.

\subsection{The Measurement of TV Public}

The most important thing that has to be taken into consideration during a TV spot is the number and composition of the public that watch the program. (George Belch, Promotion \& Advertising, 2009) In this part, we examine how to measure the public and how is used the information in setting the media planning.

The number of the public is measurable with services rating. As techniques, used to gather information for public measurement, are electronic mates or recorders and individual interviews. One of the most well know companies in this is Nielsen Media, which offers different information that can be used to measure the audience of the station. These measures are important for media consultants because they understand the value of buying during a promotion program. 


\subsection{Programs rating}

One of the most know method to measure the public is program rating, the percentage of households with television in the region that watch programs in certain times. The rating of the program is calculated by dividing the households that watch that program with the general number of households in that region. In national level, 1 point of rating 1,102,000 households. If we take as an example the most viewed program in the world "The apprentice" which has a medium rating 12 , that reaches until 13,3 million household per week $(12 \times 1,102,000)$.

The ratings are very important for networks and stations. If there is a change only of one percent in program rating during a season this can bring to the significant promotions budget profits or losses.

\section{Media Planning - Audience Calculation in Campaigns with Multiple}

\subsection{Titles - case study Bibita Group}

Analyze: the calculation of planning media audience including more than two titles taking into consideration duplications according to the formula of Agostini.

$$
\text { Net audience }=\left(\frac{1}{K(D / A)+1 A}\right)
$$

K - is constant (it depends on media \& state, and the repeated calculation from information of audience questionnaires)

A - Total audience by different titles of a planning media

D - Duplicated total 2 by 2 of these titles

Case study: lets analyze 3 titles that in the present case are identified with the letters Bibita, Nektar and Dum Dum in Kosova where the daily newspapers $\mathrm{K}=1.125$

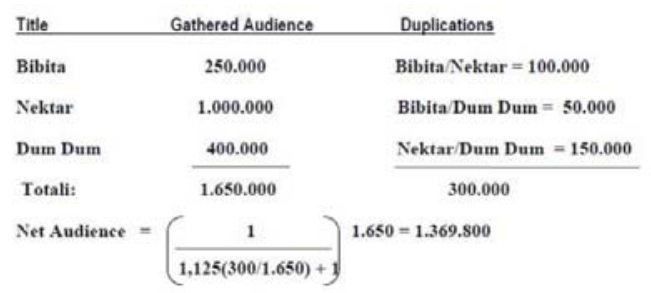

\subsection{Advertising effectiveness measurement}

Before:

- Target audience analyze (media plan)

- Creation analyze:

Semi logical analyze (meaning and connotation) and rhetorical analyze (reading level of the text, phrases and vocabulary complexity ...)

- Before testing - for example Folder tests

- Laboratory tests

After: Copy tests - campaign effective analyze

- Sales effectiveness (?) how they measure the effectiveness of communication with the consumers?

Post - tests - knowledge

- Emotional (repetitively)

- Obedience

a) The knowledge test, with an impact to the results - measure the memorization (knowledge and attributes). Starch method (of reading - viewed - written) -vs. Gallup - Robinson Method.

b) Repeated tests: 
- "Top of mind"

- Spontaneous fame

- Assisted fame

c) The evaluation "Before - After":

- Fame

- Attitude: global, according to criterions:

- Image

- Purchase goals

\subsection{Compensation of propaganda agencies}

- $\quad$ The right percentage (depending on the sales)

- Percentage + Payment

- Fix Payment: $\left(\begin{array}{l}\% \text { of budget } \\ \text { Partial work Results }\end{array}\right)$

\section{Conclusion}

This research paper aimed to explain the promotion mix and actually forms of it as, TV, radio, newspapers, and magazines, that in nowadays is considered as traditional advertisement. This form of advertisement more and more is losing its primate in the duel with promotion and other highly populated forms and very attractive for nowadays.

The promotion, if compared with that traditional, besides that its creativity, that is expressed by the marketers in their works, in the other side is the only way that provides to the consumers the possibility to have the promoted product. Furthermore, if we analyze in this case the financial aspect we can realize that the budget of the promotion is much cheaper than the promotion of the traditional forms of the same.

Table 1. The budget used for traditional advertisement by Bibita Group 2015

\begin{tabular}{|cccccc|}
\hline Year & TV & Radio & Newspapers & Billboards & Sponsoring \\
\hline 2015 & $9500 €$ & $3500 €$ & $2000 €$ & $5000 €$ & $2500 €$ \\
\hline & & & \\
\hline
\end{tabular}

Source: (Group B. , 2014) Official dates of Marketing Department in Bibita Group, December 2014

To argue the fact that the traditional promotion campaign it costs more than the promotion and we can argue that is less efficient. Following through the tables we will explain the budget used by Bibita Group, dividing the budget used for traditional advertisement and promotion:

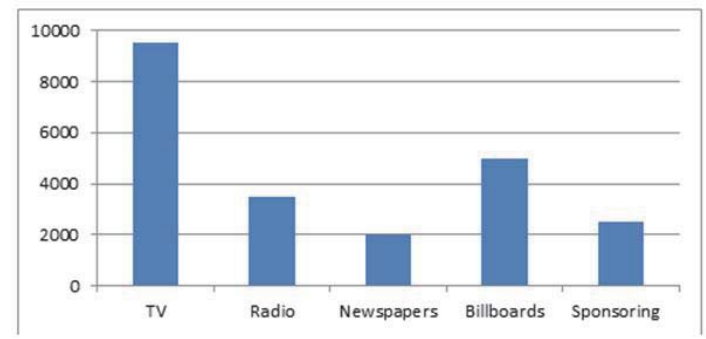

Grafic 1. The budget used for traditional advertisement by Bibita Group 2015 
Table 2. The budget used for Promotion Mix by Bibita Group, 2015

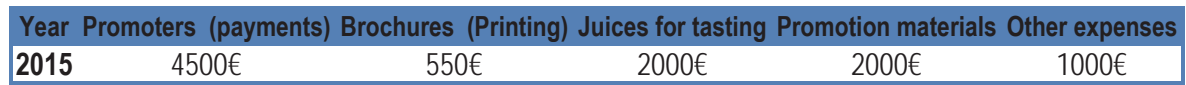

Source: (Group B. , 2014) Official dates by the Marketing Department Bibita Group, December 2014

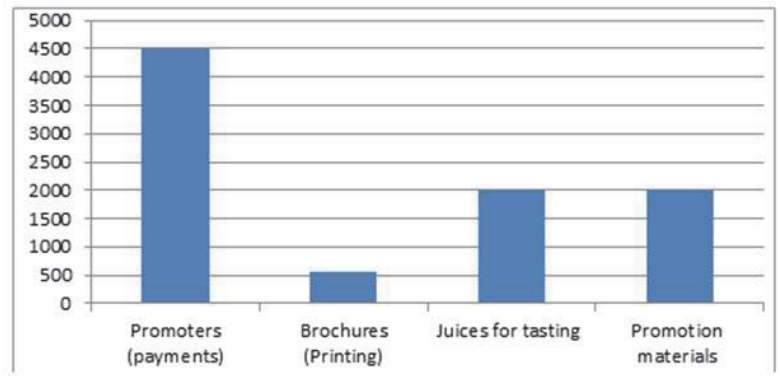

Grafic 2. The budget used for Promotion Mix by Bibita Group, 2014-2015

\section{References}

George Belch, M. B. (2009). Promotion \& Advertising. New York.

Group, B. (2014). Official dates by the Marketing Department Bibita Group, December 2014. Peje: Bibita Group.

Haresh, V. (2011). Effects of Sales Promotions on Consumer Preferences and Brand Equity Perception: with specific reference to FMCG Products. New York: FMCG.

Kotler, P. (2010). Marketing Management. New York.

Nexhbi Veseli, T. V. (2009). Marketing Management. Fry Macedonia.

Veseli, N. (2010). Promotion. Fry Macedonia.

Wallack, L. M. (2011). Mass Media Campaigns: The Odds Against Finding Behavior Change. Washington 